\title{
Assessing the Investment Attractiveness of Shares: The Joint Use of Fundamental and Technical Analysis
}

\author{
Alexander Arkadyevich Safronov ${ }^{1, *}$, Alexey Ivanovich Sazonov ${ }^{2}$ \\ ${ }^{1}$ Institute of Physics and Technology, MIREA - Russian Technological University, 78 Vernadskogo Ave., Moscow, 119454, \\ Russian Federation \\ ${ }^{2}$ Institute of Cybernetics, MIREA - Russian Technological University, 78 Vernadskogo Ave., Moscow, 119454, Russian Federation
}

Received June 1, 2021; Revised August 1, 2021; Accepted August 22, 2021

\section{Cite This Paper in the following Citation Styles}

(a): [1] Alexander Arkadyevich Safronov, Alexey Ivanovich Sazonov, "Assessing the Investment Attractiveness of Shares: The Joint Use of Fundamental and Technical Analysis," Universal Journal of Accounting and Finance, Vol. 9, No. 5, pp. 908 - 915, 2021. DOI: 10.13189/ujaf.2021.090502.

(b): Alexander Arkadyevich Safronov, Alexey Ivanovich Sazonov (2021). Assessing the Investment Attractiveness of Shares: The Joint Use of Fundamental and Technical Analysis. Universal Journal of Accounting and Finance, 9(5), 908 - 915. DOI: 10.13189/ujaf.2021.090502.

Copyright $\bigcirc 2021$ by authors, all rights reserved. Authors agree that this article remains permanently open access under the terms of the Creative Commons Attribution License 4.0 International License

\begin{abstract}
Since early 2015, the key rate of the Central Bank of the Russian Federation has been steadily decreasing. At the beginning of 2021, it amounted to $4.25 \%$ per annum, which was an unprecedented low value for the Russian economy. This conditioned a steep deposit rate fall and a significant growth in real estate prices. In the current economic situation, many private investors come to the stock market, which transforms savings into investments in the real sector of the economy. The article considers the fundamental and technical analysis of stocks. The authors have conducted a comparative analysis of shares from one industry as exemplified by PAO "Severstal", PAO "MMK" and PAO "NLMK", i.e. the leaders of the Russian ferrous metallurgy. The technical analysis of stocks is carried out on daily timeframes in the period from August 28, 2020 to March 5, 2021 using the following indicators: moving average convergence divergence (MACD), the MACD histogram and the RSI oscillator. The fundamental analysis of stocks is performed using the bottom-up method through multiples: P/E, P/S, P/BV, EV/EBITDA and EPS. The authors have concluded that it is inexpedient to invest in the shares of these companies at the current level of their capitalization.
\end{abstract}

Keywords Investments, Stock Market, Shares, Technical Analysis, Fundamental Analysis

\section{Introduction}

In the second half of 2014, the Russian ruble was depreciated by 1.5 times against the bi-currency basket due to the collapse in oil prices and the imposition of sanctions against Russia by the United States and the European Union following the events in Ukraine. Panic seized the trading floors. Foreign residents and Russian financial institutions hastily closed long positions in federal loan bonds, sub-federal, municipal and corporate bonds, as well as shares of various Russian issuers. The funds received in this case were immediately converted into dollars and euros on the currency market of the Moscow Exchange, which led to a twofold depreciation of the Russian ruble compared to the pre-crisis period. The downward movement of the Russian assets was exacerbated by the forced closure of high-risk margin trading players after a series of MarginCall notifications. In this difficult economic situation, the Central Bank of the Russian Federation raised the key rate by 6.5 bp to $17 \%$ to strengthen the ruble.

Individuals who held their money on ruble deposits at $7-8 \%$ per annum rushed to close them and withdraw cash from the banking sector to invest into assets that were traditionally considered protective in Russia during crises (currency and real estate). At the same time, professionals who had been investing in real estate for many years found themselves in a lose-lose situation since the increased key rate led to a significant increase in interest 
rates on loans, including mortgage loans. Revived in early 2015, the real estate market fell into stagnation: at best, prices did not grow; at worst, they dropped to $30 \%$ (in 2016-2017) of the pre-crisis prices and there were few buyers on the market.

Since early 2015, the key rate has been steadily decreasing. At the beginning of 2021, it amounted to $4.25 \%$ per annum. During the same period, bank deposit rates were less than $5 \%$ per annum. In this case, investments in the stock market looked quite attractive for private investors.

\section{Literature Overview}

N.A. Bogdanova defined the concept of a private investor as "an individual who invests free funds in various spheres of economy independently to make a profit". The scholar classified private investments in the following way: by income level (low, medium, high), by term (short-term, medium-term, long-term), by type (bank deposits or securities), by account (on-demand, fixed-term deposit, mortgage deposit, foreign currency account). She also discussed investments in real estate and precious metals. Moreover, she emphasized the risky nature of short- and medium-term investments in the stock market and the need to focus on long-term investments in securities [1]. We completely agree with her conclusions. Indeed, only long-term investments (starting from several years) in a well-diversified portfolio of stocks and bonds [2-4] in conjunction with the estimated residual income [5] can better protect the funds of a private investor from inflation.

While analyzing the investment processes in Russia, L.P. Badilina and N.A. Zvyagintseva referred to the issue of transforming savings (especially those of individuals) into investments in the real sector of the economy. However, the banking system cannot fully resolve this problem and the main role in this transformation is assigned to the stock market. The authors also highlighted the low use of internal investment potential in the securities market, which has a negative impact on the development of the economy since the activities of foreign residents in the Russian stock market are often short-term and speculative in the current geopolitical situation [6].

A.A. Bessonova and N.D. Belousova compared two methods of investing funds for one year. The first method is a diversified portfolio of the Moscow Exchange Blue Chips. The second method is Sberbank deposits. 35 companies were considered for the portfolio and then selected in two stages. Firstly, a part of the shares was excluded due to the statistics from the previous year and the comparison of issuers from the same industry in terms of $\mathrm{P} / \mathrm{E}$ and $\mathrm{P} / \mathrm{B}$ multiples. The portfolio comprised the remaining 14 shares according to the Markowitz model, which included shares of four companies with an annual yield of $10.43 \%$ (due to changes in the value of securities).
At the same time, the bank deposit generated only $6.1 \%$ per year. The scholars concluded that the return on a portfolio of shares was higher than a bank deposit but there was a risk of losing a part of the funds when investing in shares [7]. We disagree that the portfolio yield is calculated only based on changes in the value of securities. When calculating the total return on investment, one should consider the dividend yield of shares. In 2017 , all four companies included in the above-mentioned portfolio paid dividends, whose total return was $8.7 \%$ on invested capital per annum (after withholding a $13 \%$ tax). When selling shares that the investor has owned for less than three years and when withdrawing funds from the brokerage account, the broker withholds a part of the funds in the amount of $13 \%$ charged at the difference between sale and purchase prices for the subsequent tax payment. Thus, the total return on investment was not $10.43 \%$ but rather $10.43 \cdot 0.87+8.7=17.8 \%$, which is almost three times higher than the return on a bank deposit in the case under consideration. The broker's commission can be neglected since it amounts to about $0.06 \%$ for trading through an exchange terminal.

N.V. Kuznetsova and L.V. Kazantsev considered various risks associated with operations in the stock market. They discussed the methods of fundamental and technical analysis, compared them and revealed both positive and negative aspects of their use. As a result, they concluded that technical analysis was more suitable for short-term trading and fundamental was better for long-term investments [8]. Upon a strong growth of indices (when the market reaches new highs), risks significantly increase for holding long positions since the probability of a collapse or price correction increases, including in connection with the Covid-19 pandemic [9]. In the "high market", long-term investors should resort to technical analysis and, if necessary, reduce or close positions in trading.

\section{The Study Objective}

The study aims at developing mechanisms for selecting shares for investment from one industry.

\section{Tasks}

The tasks of the article are as follows: to explore the methods used to analyze stocks; to determine the best tools for selecting stocks from the same industry; to test the selected set of funds on several liquid stocks of the same industry.

\section{Methods}

\section{Study Design}

The methods of technical and fundamental analysis are 
used when making decisions on investing in the shares of certain companies. Technical analysis is a technique for predicting the price of an asset based on historical data on its value. The simplest methods of technical analysis boil down to building charts of price changes over a certain period (usually in the form of Japanese candlesticks). In this case, the minimum time step (timeframe) is selected. Thus, there are five-minute, hourly, daily and weekly price charts, i.e. a daily chart contains information about a change in the price of an asset over several months or years. There are two ways a price can move: in a trend or within a trading corridor. Large timeframes are usually used for long-term investments, short timeframes are better suited for short-term speculation. Using the charts showing asset prices over time, traders try to find graphical patterns, including a head and shoulders, an inverted head and shoulders, double and triple tops, double and triple bottoms, various types of triangles, etc. In addition, trend lines, channel lines, support and resistance levels, various types of moving averages, Fibonacci levels, etc. are plotted on such charts [10,11]. A separate area of technical analysis is candlestick analysis when decisions to open/close long or short positions are made based on candlestick patterns (special combinations of the Japanese candlesticks of a certain type) [12]. Candlestick analysis in conjunction with the use of technical analysis tools has proven to be advantagious.

All sorts of indicators are an important tool in the hands of a trader conducting technical analysis. At the same time, some indicators are well suited for trend following: various types of moving averages, the ADX and MACD lines, the MACD histogram, the Bollinger bands [13], etc. Another group of indicators is used when the price of an asset moves within the boundaries of a retail frontage. These are different types of oscillators: Williams' Percent Range $(\% \mathrm{R})$, the stochastic oscillator $(\mathrm{SO})$, the relative strength index (RSI), etc. Each indicator has its own characteristics. If used separately, indicators often give false signals. Therefore, when performing technical analysis, experienced traders usually use several indicators simultaneously. Oscillators are used together with trend indicators to identify their completion.

\section{Research Tools and Procedures}

Let us dwell on the indicators of technical analysis used in this article. One day serves as a timeframe.

The moving average convergence divergence (MACD) is an indicator based on the convergence and divergence of two lines (the fast line and the signal (slow) line). The fast line is the difference between the 12-day and 26-day exponential moving averages (EMA). The EMA at the time $t$ is calculated by the formula:

$$
\mathrm{EMA}_{t}=k X_{t}+(1-k) \cdot \mathrm{EMA}_{t-1}
$$

where $k=\frac{2}{N+1}$ is the smoothing coefficient $(N$ is the number of days in a given interval). The first value of this sequence (1) is calculated by the following formula:

$$
\mathrm{SMA}_{t}=\frac{\sum_{i=0}^{N-1} X_{t-i}}{N}
$$

As seen from formula (1), when calculating the EMA, the last price is taken into account more than the other prices in the interval. Accordingly, the EMA chart behaves smoothly and does not make false jumps. The signal line is the 9-day EMA of the fast line. If the fast line is above the slow one, then the trend is going up. If the slow line is above the fast one, the trend is going down. The intersection of the MACD lines indicates a trend reversal. However, the lines often "bounce" from each other and the trend continues in the same direction.

The distance between the fast and slow-moving averages indicates the strength of the trend, so it is convenient to use the MACD histogram showing the difference between the fast and slow lines. Positive values of the MACD histogram are displayed as bars in the upper (positive) half-plane, negative values are put in the lower (negative) half-plane in relation to the average zero level. If the values of the extreme points of the MACD histogram are increasing (the histogram is sloping up), then it is a bull transaction. If they are decreasing (the histogram is sloping down), it is a bear campaign. In this case, it does not matter whether the columns are located in the positive or negative half-plane. The movement of the MACD histogram indicates the ratio of buyers and sellers. The strongest signal of the MACD histogram is its divergence with prices. If the price reaches its highest/lowest point and this point is lower/higher than the previous one on the MACD histogram, then this is a strong signal to sell/buy.

The relative strength index (RSI) is one of the most known oscillators and is defined as:

$$
\mathrm{RSI}_{t}=100-\frac{100}{1+\mathrm{RS}_{t}}
$$

where $\mathrm{RS}_{t}$ is relative strength calculated by the formula:

$$
\begin{array}{r}
\mathrm{RS}_{t}=\frac{\sum_{i=0}^{N-1} \eta\left(X_{t-i}-X_{t-i-1}\right) \cdot\left(X_{t-i}-X_{t-i-1}\right)}{\sum_{i=0}^{N-1} \eta\left(X_{t-i-1}-X_{t-i}\right) \cdot\left(X_{t-i-1}-X_{t-i}\right)} \\
\eta(x)=\left\{\begin{array}{l}
0, x<0 \\
1, x \geq 0
\end{array}\right. \text { is the Heaviside step function }
\end{array}
$$

If prices in the interval only rise, then the denominator in (4) is equal to zero and $\mathrm{RS}_{t}$ stipulates division by zero. In such a situation, the RSI is assumed to be 100 . There is another way to calculate the RS, in which price changes are smoothed out by the EMA: 


$$
\mathrm{RS}_{t}=\frac{\mathrm{EMA}_{t}^{+}}{\mathrm{EMA}_{t}^{-}}
$$

where $\mathrm{EMA}_{t}^{+}$and $\mathrm{EMA}_{t}^{-}$are calculated by formula (1), in which instead of $X_{t} \eta\left(X_{t}-X_{t-1}\right) \cdot\left(X_{t}-X_{t-1}\right)$ and $\eta\left(X_{t-1}-X_{t}\right) \cdot\left(X_{t-1}-X_{t}\right)$ are used, respectively. Classically, the value of $N$ in the RSI calculations is equal to 14 . The RSI varies from 0 to 100 . Two horizontal levels are plotted on the RSI chart: the upper one denotes overbought, the lower one marks oversold. In the standard settings, these levels are equal to 70 and 30, respectively. When the indicator falls into the overbought or oversold zone, then a price reversal can be expected. In an uptrend, the RSI indicator is always in the upper area and does not go down. In a downtrend, it behaves exactly the opposite. As with the MACD histogram, the strongest signal is the RSI divergence from the prices. If the price reaches a new high/low point and the RSI value is below/above the previous point, then this is a signal to sell/buy.

The founders of fundamental analysis are Benjamin Graham and David Dodd. In 1934, they published their book "Security Analysis" [14] that uses the term financial analysis in combination with economic analysis, the analysis of capital markets, industries and securities. The results of the financial analysis should guide the selection of securities for investments, while individual and institutional investors use two approaches (top-down and bottom-up). The top-down approach first examines a general economic situation in different countries of the world, then moves on to assessing the stock and bond markets and further down the chain. The bottom-up approach immediately moves on to analyzing stocks and "pays minimum attention to common factors". The comparison of stocks from the same industry based on fundamental analysis multiples allows determining undervalued assets.

The most known multiple of fundamental analysis is $\mathrm{P} / \mathrm{E}$ which reveals the ratio of the company's capitalization to its net profit. The $\mathrm{P} / \mathrm{E}$ coefficient is actually equal to the number of years in which the money invested in the company will pay off. The main disadvantage of the $\mathrm{P} / \mathrm{E}$ indicator is the fact that it is impossible to predict a company's profit based on historical data, so companies with lower $\mathrm{P} / \mathrm{E}$ values will remain attractive for investment in case of relatively small growth. If some business is unprofitable, the $\mathrm{P} / \mathrm{E}$ value becomes negative and can no longer be used for comparison. For the Russian market of early 2021, the P/E value $<10$ for a company can be considered low and attractive for investment, the $\mathrm{P} / \mathrm{E}$ value from 10 to 20 is average, the $\mathrm{P} / \mathrm{E}$ value $>20$ indicates the overvaluation of the company's shares. It is worth mentioning that companies from different sectors of the economy are not compared in terms of their $\mathrm{P} / \mathrm{E}$ ratios.

The next $\mathrm{P} / \mathrm{S}$ multiple is equal to the ratio of capitalization to revenue. The use of this coefficient for some types of companies is not suitable since the concept of sales volume associated with the sale of goods does not apply to the insurance business or the market of credit organizations. A decrease in the $\mathrm{P} / \mathrm{S}$ indicator over several years will mean that the market capitalization lags behind the company's revenue, i.e. its underestimation. The main advantage is the fact that the P/S coefficient is always greater than zero since the sales volume is unlike profit and available for any company, i.e. all companies can be compared with the use of this multiplier. On the Russian market, the $\mathrm{P} / \mathrm{S}$ value $<1$ indicates that shares are undervalued, the $\mathrm{P} / \mathrm{S}$ value from 1 to 2 is average, the $\mathrm{P} / \mathrm{S}$ value $>2$ shows that shares are "overheated".

The $\mathrm{P} / \mathrm{BV}$ indicator is the ratio of the company's capitalization to its net assets. This multiplier shows the difference between the market and book values of the company. A negative $\mathrm{P} / \mathrm{BV}$ indicator demonstrates that the company's debt liabilities exceed its assets. The P/BV value between 0 and 1 means that the company's shares are traded at a discount. If the $\mathrm{P} / \mathrm{BV}$ coefficient is more than 1 , then the shares of such a company are expensive, and in case of bankruptcy, the value of its property will not be enough to pay off all the shareholders.

The EV/EBITDA coefficient is calculated according to the following formula:

$$
\mathrm{EV} / \mathrm{EBITDA}=\frac{\text { capitalization }+ \text { net debt }}{\text { operating income }+ \text { depreciation and amortization }}
$$

The EV/EBITDA coefficient is similar to the $\mathrm{P} / \mathrm{E}$ multiplier, it is numerically equal to the number of years over which the money invested in the company will pay off, excluding taxes, depreciation and interest on loans. It allows comparing businesses without considering taxes, debt burden and depreciation costs. This coefficient is perfect for comparing companies from the same industries in different countries since it does not consider the specifics of taxation. For the Russian market, the EV/EBITDA value $<3$ testifies to the undervaluation of a company, the EV/EBITDA value ranging from 3 to 8 is regarded as medium and the EV/EBITDA value above 8 is high.

The EPS multiplier is the ratio of the company's net profit to the number of its shares. If a joint-stock company has preferred shares, then the number of common shares is used as the EPS denominator. The EPS value can change not only due to an increase in net profit. If a company issues additional shares, the EPS coefficient will decrease. If a part of the shares is bought out, the EPS value will increase. The main feature of the EPS indicator is the fact that it is not relative but absolute. It is not appropriate to compare different companies on this basis; it is necessary to analyze the coefficient changes for one company over several years.

\section{Statistical Analysis}

Technical analysis was performed using Alfa-Direct 4.0 
trading terminal (Joint Stock Company "ALFA-BANK", Russia). Fundamental analysis was carried out using the electronic resource smart-lab.ru (project author Timofey Martynov, Russia) Accessed date was March 5, 2021.

\section{Results of Technical and Fundamental Analysis of the Shares Issued by PAO "Severstal", PAO "MMK" and PAO "NLMK"}

For example, we will analyze the shares issued by three liquid and large companies in the Russian ferrous metallurgy: PAO "Severstal", PAO "MMK" and PAO "NLMK".
We will perform a technical analysis of the shares issued by PAO "Severstal", PAO "MMK" and PAO "NLMK" according to daily charts in the period from August 28, 2020 to March 5, 2021 using the MACD averages, the MACD histogram and the RSI oscillator (Figures 1-3). We used the standard indicator settings mentioned in the methodological part. As can be seen from Figures 1-3, the indicators describe the price dynamics of the issuers in question. The intersection of the fast and slow MACD lines and the slope of the MACD-histogram correctly show the main increases and decreases in the share price, albeit with some delay. The RSI indicator reacts accurately to any change in the stock price without time lag.

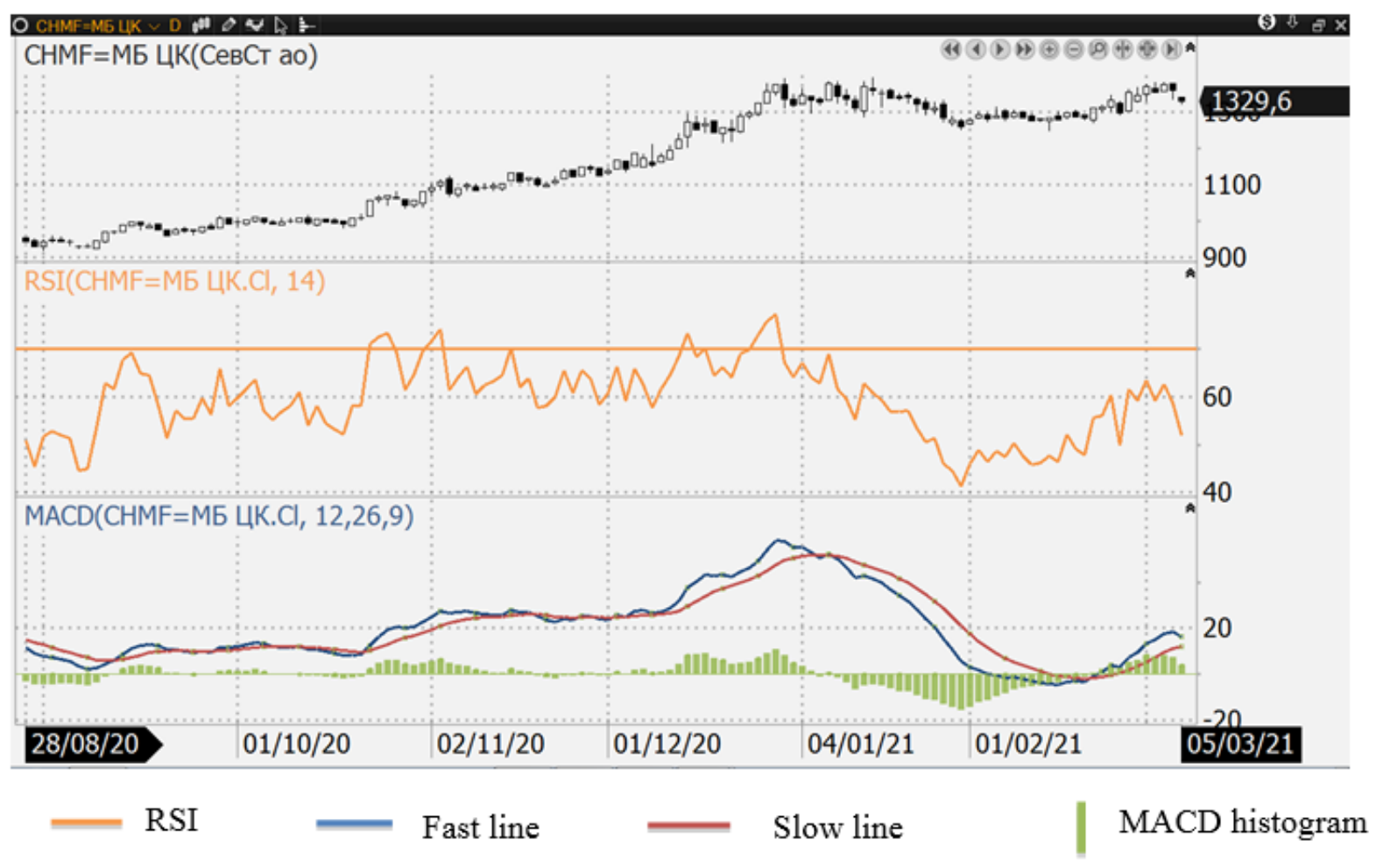

Figure 1. The technical analysis of PAO "Severstal" shares according to the daily schedule from August 28, 2020 to March 5, 2021 




Figure 2. The technical analysis of PAO "MMK" shares according to the daily schedule from August 28, 2020 to March 5, 2021

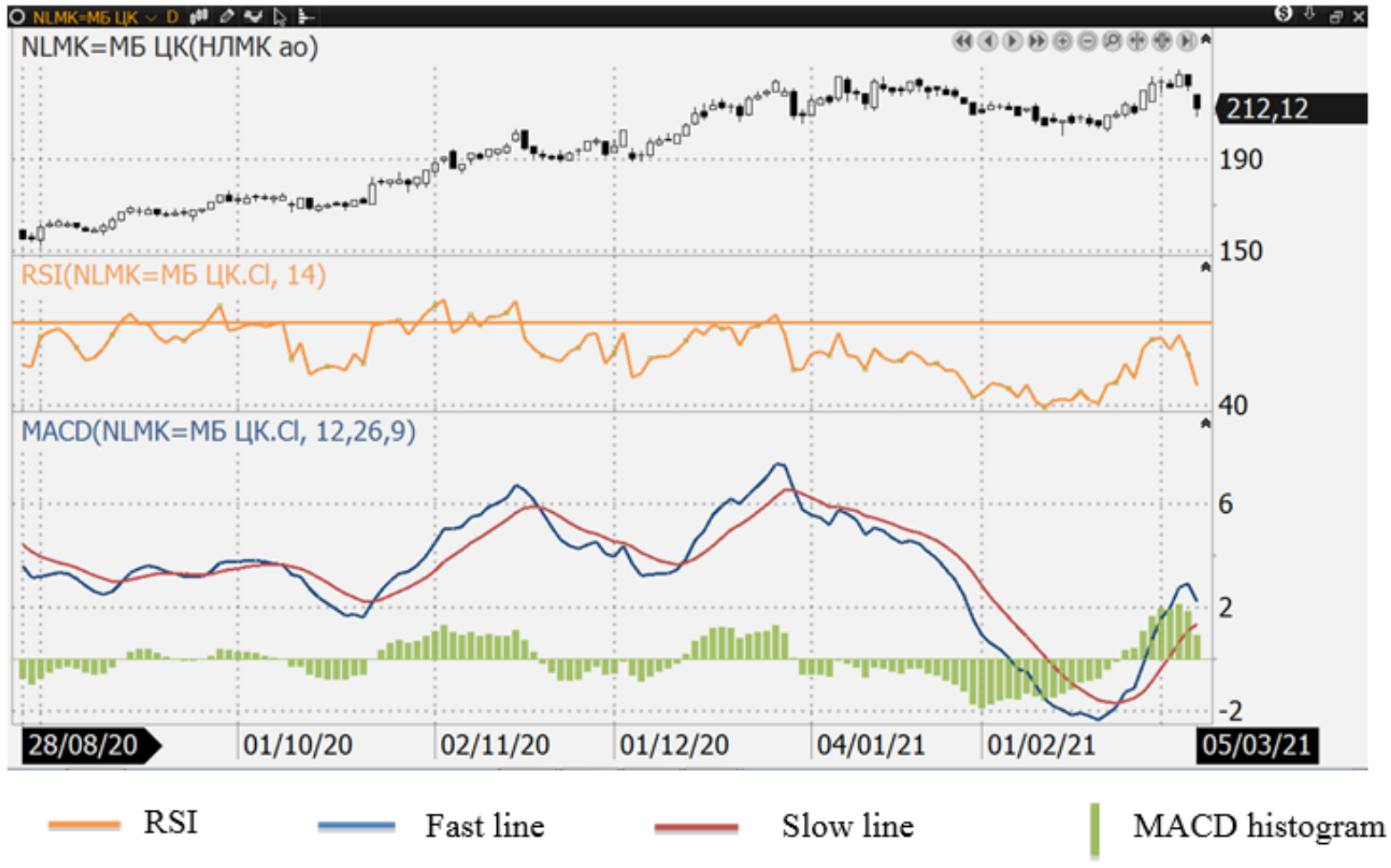

Figure 3. The technical analysis of PAO "NLMK" shares according to the daily chart from August 28, 2020 to March 5, 2021

We will perform a fundamental analysis based on five multiples: P/E, P/S, P/BV, EV/EBITDA and EPS. Let us emphasize that despite the similarity of the P/E and EPS indicators, their main difference is the fact that $\mathrm{P} / \mathrm{E}$ is a relative indicator, and EPS is an absolute one. Therefore,
$\mathrm{P} / \mathrm{E}$ allows one to compare issuers from the same sector of the economy, and EPS makes it possible to judge the dynamics of a selected company over a certain time interval. Tables 1-5 contain their values for the last five years. 
Table 1. The dynamics of changes in the P/E multiplier for PAO "Severstal", PAO "MMK" and PAO "NLMK" from 2016 to 2020

\begin{tabular}{|c|c|c|c|c|c|}
\hline $\begin{array}{c}\text { Year } \\
\text { Company }\end{array}$ & 2016 & 2017 & 2018 & 2019 & 2020 \\
\hline $\begin{array}{c}\text { PAO } \\
\text { "Severstal" }\end{array}$ & 7.73 & 7.32 & 6.06 & 6.87 & 14.90 \\
\hline PAO "MMK" & 5.00 & 6.75 & 6.36 & 8.53 & 13.5 \\
\hline $\begin{array}{c}\text { PAO } \\
\text { "NLMK" }\end{array}$ & 11.30 & 10.40 & 6.70 & 9.95 & 14.40 \\
\hline
\end{tabular}

Table 2. The dynamics of changes in the P/S multiplier for PAO "Severstal", PAO "MMK" and PAO "NLMK" from 2016 to 2020

\begin{tabular}{|c|c|c|c|c|c|}
\hline $\begin{array}{c}\text { Year } \\
\text { Company }\end{array}$ & 2016 & 2017 & 2018 & 2019 & 2020 \\
\hline $\begin{array}{c}\text { PAO } \\
\text { "Severstal" }\end{array}$ & 2.01 & 1.65 & 1.50 & 1.49 & 2.33 \\
\hline PAO "MMK" & 0.98 & 1.06 & 0.94 & 0.96 & 1.31 \\
\hline PAO "NLMK" & 1.36 & 1.50 & 1.25 & 1.26 & 2.01 \\
\hline
\end{tabular}

Table 3. The dynamics of changes in the P/BV multiplier for PAO "Severstal", PAO "MMK" and PAO "NLMK" from 2016 to 2020

\begin{tabular}{|c|c|c|c|c|c|}
\hline $\begin{array}{c}\text { Year } \\
\text { Company }\end{array}$ & 2016 & 2017 & 2018 & 2019 & 2020 \\
\hline $\begin{array}{c}\text { PAO } \\
\text { "Severstal" }\end{array}$ & 4.64 & 4.11 & 4.28 & 3.98 & 6.17 \\
\hline PAO "MMK" & 1.31 & 1.47 & 1.39 & 1.39 & 1.81 \\
\hline PAO "NLMK" & 1.92 & 2.42 & 2.50 & 2.52 & 4.17 \\
\hline
\end{tabular}

Table 4. The dynamics of changes in the EV/EBITDA multiplier for PAO "Severstal", PAO "MMK" and PAO "NLMK" from 2016 to 2020

\begin{tabular}{|c|c|c|c|c|c|}
\hline $\begin{array}{c}\text { Year } \\
\text { Company }\end{array}$ & 2016 & 2017 & 2018 & 2019 & 2020 \\
\hline $\begin{array}{c}\text { PAO } \\
\text { "Severstal" }\end{array}$ & 6.56 & 5.35 & 4.43 & 4.87 & 7.29 \\
\hline PAO "MMK" & 2.93 & 3.94 & 3.19 & 3.91 & 5.56 \\
\hline PAO "NLMK" & 6.16 & 6.45 & 4.46 & 5.86 & 8.05 \\
\hline
\end{tabular}

Table 5. The dynamics of changes in the EPS multiplier for PAO "Severstal", PAO "MMK" and PAO "NLMK" from 2016 to 2020

\begin{tabular}{|c|c|c|c|c|c|}
\hline $\begin{array}{c}\text { Year } \\
\text { Company }\end{array}$ & 2016 & 2017 & 2018 & 2019 & 2020 \\
\hline $\begin{array}{c}\text { PAO } \\
\text { "Severstal" }\end{array}$ & 121.9 & 121.2 & 155.5 & 136.4 & 89.1 \\
\hline PAO "MMK" & 6.65 & 6.20 & 6.76 & 4.92 & 3.91 \\
\hline $\begin{array}{c}\text { PAO } \\
\text { "NLMK" }\end{array}$ & 10.1 & 14.1 & 23.5 & 14.4 & 14.9 \\
\hline
\end{tabular}

\section{Discussion}

The visual analysis of the above-mentioned charts reveals a strong correlation of three companies in a given time interval, therefore, the indicators of technical analysis are almost identical. From mid-October to the end of December, their shares experienced a strong upward movement: the shares of Severstal increased by $42 \%$, the shares of MMK by $71 \%$ and the shares of NLMK by $34 \%$. The stock prices of all companies reached their all-time highest values. At the beginning of the trend, the fast line crossed the slow one from the bottom up and did not go below the slow one throughout the trend (except for three weeks in the case of NLMK). At the same time, the RSI index was constantly in the upper level and often got into the overbought zone, which was its usual behavior during an uptrend. We use the RSI as a filter, that is, we don't buy (don't sell) if the RSI is in the overbought (oversold) zone. As can be seen from Figures 1-3, in mid-October, when the fast line crosses the slow one from the bottom up (while the MACD histogram, falling below zero, begins to rise), the RSI index for all three issuers is not in the overbought zone, which serves as a buy signal. In early January, the fast line crosses the slow one from top to bottom, the RSI index is not in the oversold zone, which is a signal to close a long position and open a short one, which, according to the indicators, should have been closed in the second half of February. In the case of Severstal and MMK shares, the deal would have brought a small profit, for NLMK it would have been a breakeven. As one can see from Figure 3, opening a three-week short position on the indicators in mid-November for NLMK would lead to insignificant losses, which confirms the belated reaction of the MACD. The aforementioned short trades against the main trend are highly speculative and are considered solely as part of assessing how our chosen indicators are performing. Analyzing Figures 1-3 in hindsight, it is clear that with January to early March, the prices of all three groups entered the trading corridor. At the end of January, the shares had a correction of about $10 \%$. In mid-February, their growth resumed. In early March, the price "bounced" from the upper border of the trading corridor, while the RSI index failed to reach the overbought zone and took a neutral position on March 5, 2021. The MACD histogram was inclined downward in the first days of March. The fast line approached the slow one.

As can be seen from Table 1, the P/E indicator of NLMK was significantly higher than that of Severstal and MMK in 2016 and 2017. In 2018, it fell and all the companies under review had almost the same values. This is due to a general decline in markets during this year. During this period, the RTS index dropped to 1,070 points. Over 2020, the P/E coefficient of the three companies grew significantly if compared to 2019 (from 1.5 to 2 times) and again equalized.

Table 2 shows that the P/S value of all three companies remained practically unchanged during 2017-2019. In 2020, it increased: by $56 \%$ for PAO "Severstal", by $36 \%$ for PAO "MMK", by 59\% for PAO "NLMK". Currently, the $\mathrm{P} / \mathrm{S}$ value of MMK looks more attractive in comparison with the other metallurgical plants. However, the shares of MMK cannot be called undervalued. The P/S indicators of Severstal and NLMK are more than two, which indicates that the market overestimates these companies.

As can be seen from Table 3, the shares of all the issuers look overvalued since their $\mathrm{P} / \mathrm{BV}$ values $>1$. Over 
the past year, the $\mathrm{P} / \mathrm{BV}$ indicator has grown for all three companies. The growth was 55\% for PAO "Severstal", $30 \%$ for PAO "MMK", $65 \%$ for PAO "NLMK". Over five years, the P/BV values of Severstal have been significantly higher than those of MMK and NLMK. MMK has the lowest P/BV value of all three companies.

Table 4 demonstrates that the EV/EBITDA ratio for the companies under consideration is currently in average values. It has reached its upper limit for Severstal and NLMK. In the period from 2016 to 2019, this multiplier had relatively low absolute values for MMK if compared to Severstal and NLMK. Over the past year, the EV/EBITDA value has grown significantly: by $50 \%$ for PAO "Severstal", $42 \%$ for PAO "MMK", 37\% for PAO "NLMK".

According to Table 5, Severstal and MMK have similar EPS dynamics. In 2016-2017, the indicator remained almost constant. In 2018, it reached its maximum value. In 2019-2020, it decreased. If compared to 2019, the decline in the EPS value was $53 \%$ for Severstal and $25 \%$ for MMK in 2020. The EPS indicator of NLMK showed positive dynamics from 2016 to 2018: in 2017, the ratio increased by $40 \%$ if compared to 2016; in 2018, its growth was $67 \%$ if compared to 2017. In 2019, it dropped to the level of 2017. In 2020, the EPS indicator of NLMK remained almost unchanged if compared to 2019.

\section{Conclusions}

After the technical and fundamental analysis of three major representatives of the Russian ferrous metallurgy industry (Severstal, MMK and NLMK), we have concluded that it is inexpedient to invest in the shares of these companies and necessary to wait for a price correction. At the current level of their capitalization (as of the beginning of 2021), the purchase of their shares can be extremely high-risk and speculative. The joint application of both fundamental and technical analysis has proved its efficiency and can be used to consider stocks from the same industry. According to this approach, the risk of partially losing funds is inversely proportional to the duration of investments. Investing in shares for three years or more is relatively safe.

In the future, we will continue to research investment issues. It is planned to study the dynamics of companies from different sectors of the economy, if possible with a negative correlation, to increase the efficiency of the investment portfolio.

\section{REFERENCES}

[1] N. A. Bogdanova. Chastnye investitsii kak element finansov fizicheskikh lits [Private investments as a component of the individual's funds], Vestnik RGGU. Seriya "Ekonomika. Upravlenie. Pravo", No.1, 36-43, 2015.

[2] A. E. Barysheva, A. S. Markov, A. A. Mitcel. Otsenka VaR pri negaussovom raspredelenii dokhodnostei aktivov [VAR assessment under nongaussian distribution of returns], Russian Technological Journal, Vol.8, No.2, 67-84, 2020. https://doi.org/10.32362/2500-316X-2020-8-2-67-84

[3] Y. E. Putra, D. Saepudin, A. Aditsania. Portfolio Selection of KOMPAS-100 stocks index using B-spline based clustering, Procedia Computer Science, No.179, 375-382, 2021.

[4] S. Pysarenko, V. Alexeev, F. Tapon. Predictive blends: fundamental indexing meets Markowitz, Journal of Banking \& Finance, Vol.100, 28-42, 2019.

[5] N. Weining. Equity Valuation with Heterogeneous Beliefs, Universal Journal of Accounting and Finance, Vol.9, No.2, pp.204-209, 2021. DOI: 10.13189/ujaf.2021.090209

[6] L. P. Badilina, N. A. Zvyagintseva. Aktivizatsiya investitsionnykh protsessov $\mathrm{v}$ Rossiiskoi Federatsii $\mathrm{s}$ ispolzovaniem rynka tsennykh bumag [Launching investments in the Russian Federation with the help of the security market], Izvestiya Irkutskoi gosudarstvennoi ekonomicheskoi akademii, Vol.26, No.1, 5-14, 2016.

[7] A. A. Bessonova, N. D. Belousova. Razmeshchenie svobodnykh denezhnykh sredstv fizicheskikh lits: depozity i tsennye bumagi [The placement of disposable monetary resources of individuals: deposits and securities], Azimut nauchnykh issledovanii: ekonomika i upravlenie, Vol.7, No.2(23), 48-51, 2018.

[8] N. V. Kuznetsova, L. V. Kazantsev. Fundamentalnyi i tekhnicheskii analiz fondovogo rynka [The fundamental and technical analysis of the stock market], Baikal Research Journal, Vol.7, No.5, 4, 2016. https://doi.org/10.17150/241 $1-6262.2016 .7(5) .4$

[9] M. Azis, Burhanuddin, H. Rahayu. Stock Price of Pandemic Covid-19 in Stock Market Performance, Universal Journal of Accounting and Finance, Vol.9, No.2, pp.184-190, 2021. DOI: 10.13189/ujaf.2021.090206

[10] J. Murphy. Tekhnicheskii analiz fyuchersnykh rynkov [Technical analysis of the financial markets], translated by N. Konevskaya, Izdatelstvo "Vilyams", Moscow, 2020, 496 p.

[11] A. Elder. Kak igrat i vyigryvat na birzhe [How to play and win at the stock exchange], translated by M. Volkova, A. Volkov, Izdatelstvo "Alpina Pablisher", Moscow, 2020, $471 \mathrm{p}$.

[12] S. Nison. Yaponskie svechi [Japanese candlestick], translated by T. Dozorova, M. Volkova, Izdatelstvo "Alpina Pablisher", Moscow, 2020, 430 p.

[13] N. Yensen, D. Min-Yuh, H. Paoyu, Y. Shang-Ru. The profitability of Bollinger Bands: Evidence from the constituent stocks of Taiwan 50, Physica A: Statistical Mechanics and its Applications, Vol.551, 124-144, 2020.

[14] B. Graham, D. Dodd. Analiz tsennykh bumag [Security analysis], translated by A. Nazarenko, O. M. Pelyavskii, Izdatelstvo "Vilyams", Moscow, 2017, 880 p. 